\title{
AFTERSHOCK DISTRIBUTION OF THE 1983 JAPAN SEA EARTHQUAKE AS DETERMINED FROM HELICOPTER-DISPATCHED OBS OBSERVATION
}

\author{
Taku Urabe, ${ }^{*}$ Kiyoshi SuYehiro,**,1) Takaya Iwasakr,*** \\ Naoshi HrRata, ${ }^{* * * *}$ Toshihiko KanazaWa, ${ }^{* * * *}$ Azusa NishizaWA, ${ }^{* *}$ \\ and Hideki SHIMAMURA*** \\ *Department of Physics, Kyushu University, Fukuoka, Japan \\ **Observation Center for Earthquake Prediction, Faculty of \\ Science, Tohoku University, Sendai, Japan \\ ***Laboratory for Ocean Bottom Seismology, Faculty of Science, \\ Hokkaido University, Sapporo, Japan \\ ****Geophysical Institute, Faculty of Science, the University of \\ Tokyo, Tokyo, Japan
}

(Received November 22, 1984; Revised February 22, 1985)

Five ocean bottom seismographs (OBSs) were dispatched to the source region of the 1983 Japan Sea earthquake (occurred on May $26 ; M=7.7$ ) by a helicopter only three days after the mainshock. The source region was 40 to $100 \mathrm{~km}$ off the western coast of northern Honshu. The major part of the aftershock area was covered by the OBS network, which recorded ground motion on magnetic tape continuously for 12 days. Among the vast number of aftershocks recorded, 500 events were selected for reproduction. A precise aftershock distribution was obtained from these data. The aftershock area, which ran along the eastern margin of the Japan Basin, was $140 \mathrm{~km}$ long in north-south with a width of $40 \mathrm{~km}$. The focal depths of the aftershocks were concentrated in a range of 8 to $21 \mathrm{~km}$. Since the lithosphere of this region is estimated to be no less than $30 \mathrm{~km}$ thick, the fracture did not span the entire lithosphere. The geometry of the main fault was suggested by a plane arrangement of the aftershock distribution, which is $30 \mathrm{~km}$ long in north-south and dips eastward by 15 to $25^{\circ}$. This observation is consistent with the mechanism solution of the mainshock obtained from land data. Not a few hypocenters which do not belong to the eastward-dipping plane may suggest the existence of another major fault plane.

\section{Introduction}

The 1983 Japan Sea earthquake, $M=7.7$ as determined by the Japan Meterological Agency, occurred on May 26 off the western coast of northern Honshu, Japan. The source region of the earthquake is along the eastern margin of the

1) Now at Department of Earth Sciences, Faculty of Science, Chiba University, Chiba, Japan 
Japan Basin, which is the backarc basin of the Northeastern Japan Arc. The depth for the most part of the Japan Basin ranges from 3,000 to 3,500 m, and is shallower in the margin. The topography of the source region is characterized by small ridges, troughs, and active faults which run generally in a north-south direction and also in parallel with the northeastern Japan Arc. The crust of the Japan Basin is estimated to have a typically oceanic structure with a thickness of about $9 \mathrm{~km}$ (LuDwig et al., 1975). It contrasts well with that of inland northeastern Japan which is estimated to be $30 \mathrm{~km}$ thick (YosHII and ASANO, 1972). The lithosphere of the Japan Sea is estimated to be $30 \mathrm{~km}$ thick or more (ABE and KANAMORI, 1970; EVANS et al., 1978).

The seismicity of the eastern margin of the Japan Sea is much lower than that off the Pacific coast of Honshu, namely, the Japan Trench area. However, historical data show that the eastern margin of the Japan Sea forms a certain seismic belt in comparison with the other part of the Japan Sea and northern Honshu inland. Several events of magnitude greater than 7 have occurred in the belt: the Takada earthquake in $1614(M=7.7)$, the Oshima tsunami-earthquake in 1741 $(M>7.5)$, the Off-Yamagata earthquake in $1833(M=7.6)$, the Off-Shakotan earthquake in $1940(M=7.5)$, and the Niigata earthquake in $1964(M=7.5)$ (HATORI and KaTAYAMA, 1977). The source region of the 1983 Japan Sea earthquake did not overlap with those of these earthquakes. The 1964 Off-Oga earthquake ( $M=6.9$ ) occurred in the source region of the 1983 Japan Sea event; its magnitude is much smaller than that of the 1983 event, however. Therefore there had been no large earthquake comparable to the 1983 event in its source region for at least the last 300 years.

The mechanism solutions have been obtained for the most recent three of the above-mentioned earthquakes; the 1940 Off-Shakotan earthquake by FuKAO and Furumoto (1975), the 1964 Off-Oga earthquake by ICHIKAWA (1971), and the 1964 Niigata earthquake by ABE (1975). Their results show that the mechanisms of these earthquakes are almost pure dip-slip type, with pressure axes directing east-west.

In this study we deduce the geometry of the fracture of the 1983 Japan Sea earthquake from a precise aftershock distribution obtained from an observation by ocean bottom seismographs (OBSs). This is the best and only possible way to obtain the fault geometry of an earthquake at sea area because no reliable geodetic data are available there.

Here, it is supposed that the aftershocks are distributed more densely along the larger fracture surfaces, that is, the major fault planes. In this sense, it is important to observe the aftershocks immediately after the occurrence of the mainshock, because aftershock activities often spread out with time so that their pattern of distribution changes. Development of compact OBSs made it possible to dispatch an OBS array for an aftershock observation shortly after the occurrence of a large earthquake in the sea area. At the 1978 Miyagi-Oki earthquake $(M=7.4)$, 
three tethered OBSs were deployed using a 180-ton ship 16 days after the occurrence of the mainshock to observe its aftershocks (YAMADA et al., 1978; MATSU'URA et al., 1978; YAMADA, 1980). IwASAKI et al. (1983), at the Urakawa-Oki earthquake $(M=7.1)$, used a 17-ton fishing boat to deploy four compact pop-up OBSs eight days after the mainshock. Their studies have shown the effectiveness of the use of OBSs for accurate aftershock locations, especially in determining focal depths, in comparison to those obtained from land data alone.

In the 1983 Japan Sea earthquake, the aftershock region was a sea area 40 to $100 \mathrm{~km}$ off the western coast of Honshu, so that the use of OBSs in the aftershock observation was thought to be essential in obtaining a precise aftershock distribution. In the present study, five OBSs were dispatched by a helicopter to the source area only three days after the occurrence of the main shock. A precise distribution of the aftershocks was obtained from a 12-day observation by the OBS array, and it was used to deduce the fault plane geometry of the mainshock.

\section{Observation}

Five OBSs were deployed on May 29, three days after the occurrence of the main shock. In consideration of cost, speed, and convenience, a helicopter (Aerospatial SA330 Puma) was used in the deployment. The OBSs were assembled at a heliport in Tokyo on May 28. The next morning the helicopter, loaded with OBSs which were ready for launch, was flown $400 \mathrm{~km}$ north to Akita airport, near the source region. In the afternoon the helicopter took off for the observation area, deployed the five OBSs and returned to Akita airport again in three hours. The round trip flight distance was about $400 \mathrm{~km}$. The Omega navigation system was used in the positionings to launch the OBSs at the scheduled points. At the launching, an OBS was suspended from a wire rope and was lowered to the sea surface by an electric winch, while the helicopter was hovering at about $50 \mathrm{~m}$ above the sea surface. The hook between the wire rope and the OBS was remotely released as the OBS entered the water. The time required to launch the OBS at a site was less than $5 \mathrm{~min}$.

The OBSs were of a pop-up type with a timed release (YAMADA et al., 1981; URABE and KANAZAWA, 1984). Each weighed $80 \mathrm{~kg}$ in air and was $70 \mathrm{~cm}$ cubic in size before launch. Because of the light weight and the small size, the five OBSs could be transported in the passenger cabin of the helicopter together with six people.

All the OBSs were successfully recovered on June 10 to 11 by R/V Shoyo, which belongs to the Hydrographic Department of the Japan Maritime Safety Agency. The positionings at the recovery were done using the NNSS (Navy Navigation Satellite System) and ranging and hyperbolic modes of the Loran-C. The ocean currents were small and the OBSs were immediately located after the surfacing. Since the positioning accuracies at the recovery were better than those at the launch made by the Omega system, we adopted the positions and the water 


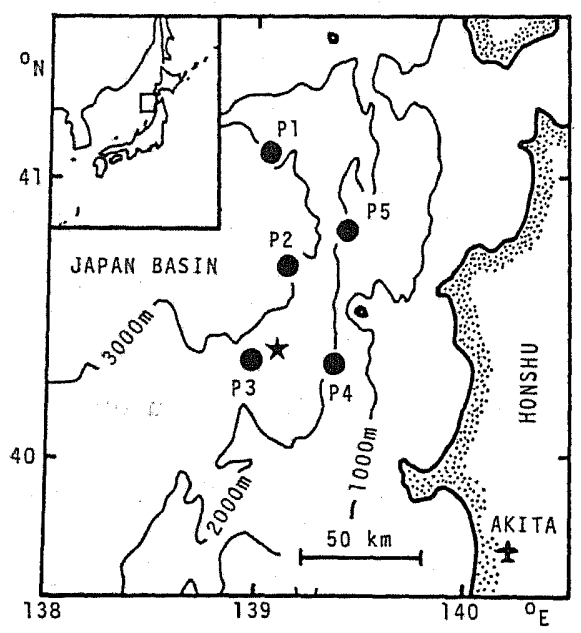

Fig. 1. Locations of OBS stations (P1 through P5; solid circles) and epicenter of the main shock determined by the OCEP of Tohoku University (star). Location of Akita airport is also shown.

depths measured at the recovery as those of the OBSs in the hypocenter determination calculation. The errors of the positions of the OBSs are estimated to be less than $0.2 \mathrm{~km}$.

The locations of the five OBS stations, which were named P1 through P5, are shown in Fig. 1 and listed in Table 1. In order to cover most of the aftershock area with the OBS array, the aftershock distribution preliminarily determined by the land seismographic network of the Observation Center for Earthquake Prediction (OCEP) of Tohoku University was referred to. The average spacing between the OBS's was about $40 \mathrm{~km}$. The water depths of the OBS sites ranged from 2,000 to $3,000 \mathrm{~m}$.

Each OBS has vertical and a horizontal geophones. Ground motion is continuously recorded on a Philips-type cassette tape by an analog direct recording method. The recorder has four recording channels, which are assigned to a lowgain vertical component, high-gain vertical component, horizontal component, and BCD coded clock signal. The frequency response of the OBS system is 3 to $22 \mathrm{~Hz}(-3 \mathrm{~dB})$ for the vertical components and 4.5 to $22 \mathrm{~Hz}(-3 \mathrm{~dB})$ for the horizontal component.

The clock of the OBS system has a stability of $5 \times 10^{-7}$ through a temperature range of 0 to $50^{\circ} \mathrm{C}$. It was calibrated before the launch and after the recovery against the standard time (JJY radio signal) so that the timing accuracy of $0.01 \mathrm{~s}$ was maintained throughout the observation.

According to Faculty of ScIENCE, TohokU UNIVERSITy AND FACULTY OF SCIENCE, HIROSAKI UNIVERSITY (1984), the daily frequency of the aftershocks decreased exponentially after the mainshock. On June 9, two large aftershocks 


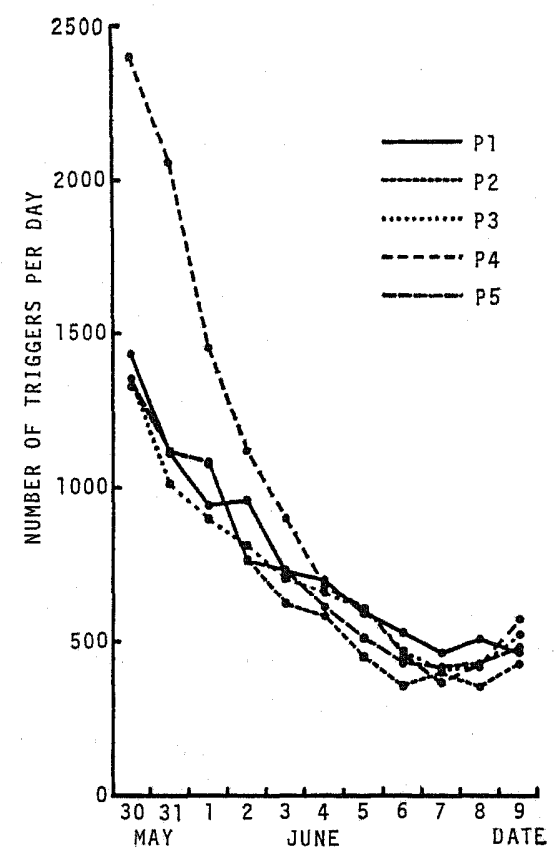

Fig. 2. Daily number of events selected from each of the OBS stations. Threshold of a combination of amplitude level and duration time was used as the criterion for the selection.

$(M=6.1$ and 6.0, after JMA) occurred at the southern end of the aftershock area. The frequency of the aftershocks increased to some extent and decreased again. The largest aftershock with magnitude 7.1 occurred at the northern end of the aftershock area on June 21, after the OBS observation (from May 29 to June 10). After the occurrence of these large aftershocks, the aftershock area extended both northward and southward for about $20 \mathrm{~km}$ each (FACULTY OF SCIENCE, TOHOKU UNIVERSITY aNd FACULTY OF SCIENCE, Hirosaki UNIVERSITY, 1984).

\section{Data}

A vast number of aftershocks were recorded by the OBSs. Distinguishable earthquakes were observed every minute. In addition, waves of many undistinguishable earthquakes were recorded continuously, so that they formed a large background noise. This phenomenon was remarkable especially in the early days of the observation period.

To obtain the aftershock distribution, we used the following method. The data were processed with the computer-aided system developed by URABE and Hirata (1984).

(1) Earthquakes were selected by an automatic event detection for each sta- 


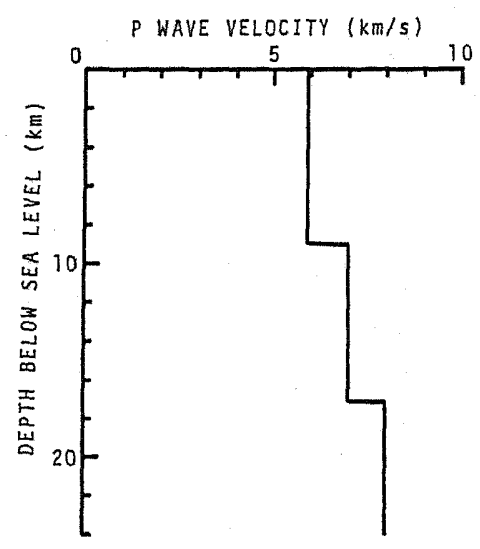

Fig. 3. P-wave velocity structure model used in the hypocenter determination.

tion. A fixed threshold of a combination of the amplitude level and the duration time of the event was used in the detection for all the stations. The daily number of the selected events is presented for each station in Fig. 2. The total number of these events for each station ranged from 1,600 to 2,500. In Fig. 2, the number of the selected events decreased nearly exponentially except for the last two days of the observation period when it increased. This increase is remarkable at the southern stations (P3 and $\mathrm{P} 4$ ), and it corresponds to the activity at the southern end of the aftershock area which accompanied the two large aftershocks mentioned above.

(2) The earthquakes selected at all five stations in common were picked up for hypocenter determination. About 500 events were selected in this stage. The magnitudes of these events were estimated to be greater than about 3 after those of the corresponding events determined by the OCEP of Tohoku University.

(3) The records of the selected 500 events were digitized from the original tapes, after which visual records were made with a paper recorder. In order to facilitate reading seismic phases, the traces of the five OBS stations were arranged on a paper to have a common time axis for each event, like a record from a telemetered network, by digital data processing. The clock of each OBS was corrected for the drift at a constant rate during the operation at the bottom.

(4) The arrival times of the $P$ and $S$ waves of the 500 events were digitized manually from the paper records. Hypocenter determination was carried out for 442 events whose $P$ arrival times were picked with accuracy better than $0.1 \mathrm{~s}$ at four or five OBS stations. The $\mathrm{P}$ arrival times with estimated accuracy worse than $0.1 \mathrm{~s}$ were not used in order to keep the quality of the result high. A formulation of inversion analysis by MATSU'URA and HIRATA (1982) was used in the computer program of the hypocenter determination.

Most of the earthquake wave records were saturated with their amplitude after the $P$ arrivals so that the $S$ arrivals were generally unable to be picked with ac- 


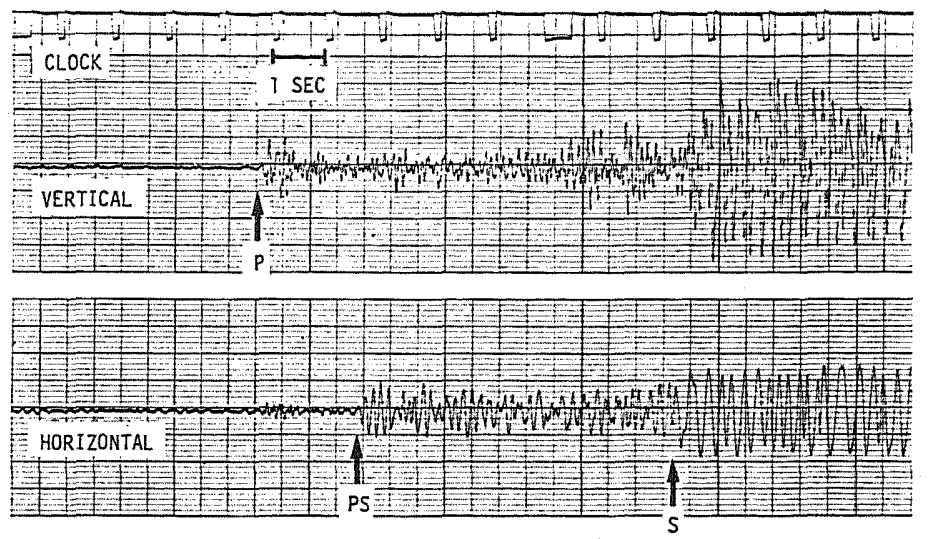

Fig. 4. An example of a phase converted from $P$ wave to $S$ wave at the bottom of the sediment-basement boundary (designated by "PS"). $\mathrm{P}$ and $\mathrm{S}$ arrivals are also disignated by "P" and "S", respectively. Vertical and horizontal components are shown. The record is from station P1 at 14: 03, June 1, 1984 (JST).

ceptable accuracy. This was because we selected comparatively large events, and there was only one horizontal channel so the dynamic range was limited. For this reason and because the S-wave velocity structure was not known, the $S$ arrivals were used only to give the initial value of the origin time in the hypocenter calculation.

The P-wave velocity structure of the source area has not been clearly resolved. The best available data are the result of a time-term study by YosHII and ASANO (1972). Their profile runs through the southernmost part of the aftershock area. We adopted their result as the averaged crustal structure model of the source region. The Moho is at $17 \mathrm{~km}$ below the sea level. The $P_{n}$ velocity was assumed to be $8.0 \mathrm{~km} / \mathrm{s}$ after OKADA et al. (1978). The P-wave velocity structure model used in the hypocenter determination is shown in Fig. 3.

The contribution of the sedimentary layer was estimated and compensated before the hypocenter calculation. The method is as follows. There are two sets of data which offer information about the sedimentary layer. One is the arrival time difference between the $\mathrm{P}$ phase and the phase converted from $\mathrm{P}$ wave to $\mathrm{S}$ wave at the bottom of the sediment, $T_{\mathrm{PS}-\mathrm{P}}$. This converted phase was clearly observed at all the stations, and the $T_{\mathrm{PS}-\mathrm{P}}$ 's were almost constant for each station. An example of the converted phase is shown in Fig. 4. Since the $V_{\mathrm{P}}$ and $V_{\mathrm{S}}$ of the sedimentary layer are small, the paths of the incident rays in the sedimentary layer are nearly vertical. Thus the time difference $T_{\mathrm{PS}-\mathrm{P}}$ is written as

$$
T_{\mathrm{PS}-\mathrm{P}}=T_{\mathrm{P}}\left(V_{\mathrm{P}} / V_{\mathrm{S}}-1\right),
$$

where $T_{\mathrm{P}}, V_{\mathrm{P}}$, and $V_{\mathrm{S}}$ are the $\mathrm{P}$ wave travel time, $\mathrm{P}$-wave velocity, and $\mathrm{S}$-wave velocity in the sedimentary layer, respectively.

Another data set of the sedimentary layer is the two way reflection time data 
Table 1. Locations and parameters of sediments of OBS stations.

\begin{tabular}{lccccc}
\multicolumn{1}{c}{ Station code } & P1 & P2 & P3 & P4 & P5 \\
\hline Latitude $\left({ }^{\circ} \mathrm{N}\right)$ & 41.0958 & 40.6942 & 40.3558 & 40.3483 & 40.8183 \\
Longitude $\left({ }^{\circ} \mathrm{E}\right)$ & 139.0433 & 139.1500 & 138.9750 & 139.3700 & 139.4417 \\
Height $(\mathrm{km})$ & -2.86 & -3.07 & -2.42 & -2.02 & -2.07 \\
$T_{\mathrm{PS}-\mathrm{P}^{*}}(\mathrm{~s})$ & 1.86 & 2.00 & 1.79 & 1.28 & 1.46 \\
$T_{\mathrm{P}}{ }^{* * *}(\mathrm{~s})$ & - & 0.40 & 0.30 & 0.25 & 0.50 \\
$V_{\mathrm{P}} / V_{\mathrm{S}}{ }^{* * *}$ & - & 6.0 & 7.0 & 6.1 & 3.9 \\
$T_{\mathrm{P}}{ }^{* * * * *}(\mathrm{~s})$ & 0.34 & 0.37 & 0.33 & 0.24 & 0.27 \\
Sediment thickness $(\mathrm{km})$ & 0.68 & 0.74 & 0.66 & 0.48 & 0.54 \\
Reduced height $(\mathrm{km})$ & -3.54 & -3.81 & -3.08 & -2.50 & -2.61 \\
\hline
\end{tabular}

* Observed from OBS data. ** Interpolated from acoustic survey data. *** Calculated from $T_{\mathrm{PS}-\mathrm{P}} *$ and $T_{\mathrm{P}} * *$. ***** Calculated by using $T_{\mathrm{PS}-\mathrm{P}}$. and assuming $V_{\mathrm{P}} / V_{\mathrm{S}}=6.4$.

$\left(2 T_{\mathrm{P}}\right)$ of the top of the acoustic basement obtained from a seismic profiler survey made by R/V Shoyo. Although the survey lines did not run exactly over OBSs, we tried to estimate the $P$ wave travel times in the sedimentary layer, $T_{\mathrm{P}}$ 's, at the OBS stations by interpolation and extrapolation of the data. The station PI was excepted from the estimation because it was far from the survey area.

The $V_{\mathrm{P}} / V_{\mathrm{S}}$ ratio of the sedimentary layer was calculated from the observed $T_{\mathrm{PS}-\mathrm{P}}$ and the estimated $T_{\mathrm{P}}$, for each of the four stations P2 through P5. The average $V_{\mathrm{P}} / V_{\mathrm{S}}$ of 6.4 was obtained from the stations $\mathrm{P} 2, \mathrm{P} 3$, and $\mathrm{P} 4$. The $V_{\mathrm{P}} / V_{\mathrm{S}}$ obtained for P5 was excepted because the $V_{\mathrm{P}} / V_{\mathrm{S}}$ ratio of 3.9 seemed too small in comparison with those obtained for the other three stations. We attributed this small $V_{\mathrm{P}} / V_{\mathrm{S}}$ value to the inaccurate estimation of the $T_{\mathrm{P}}$, because the spatial interpolation of the acoustic survey data might have caused the error. The $V_{\mathrm{P}} / V_{\mathrm{S}}$ of 6.4 was used, in turn, to estimate $T_{\mathrm{P}}$ from the $T_{\mathrm{PS}-\mathrm{P}}$ data observed at each of the five stations. The thickness of the sedimentary layer was calculated by assuming $V_{\mathrm{P}}=2.0 \mathrm{~km} / \mathrm{s}$ as a typical value. The data and the results are tabulated in Table 1. Possible errors in the velocity structure model affect the depths of the hypocenters in a systematic way by 2 or $3 \mathrm{~km}$; however, they do not significantly change the pattern of the distribution.

The velocity structure model has no sedimentary layer. In the hypocenter determination, the elevations of the stations were subtracted by the estimated thickness of the sediment, and the $\mathrm{P}$ arrival times were subtracted by the estimated $T_{\mathrm{P}}$. The S-P times were subtracted by $T_{\mathrm{PS}-\mathrm{S}}$, and were used to give the initial origin time. In this manner the contribution of the sedimentary layer was excluded so that the observation sites were virtually placed on the top of the basement layer.

The hypocenter of the corresponding earthquake determined by the land network of the OCEP of Tohoku University was adopted as an initial hypocenter in the hypocenter determination calculation. The initial origin time was estimated and given from the S-P time of the OBS data by assuming $V_{\mathrm{P}} / V_{\mathrm{S}}=1.73$. The 


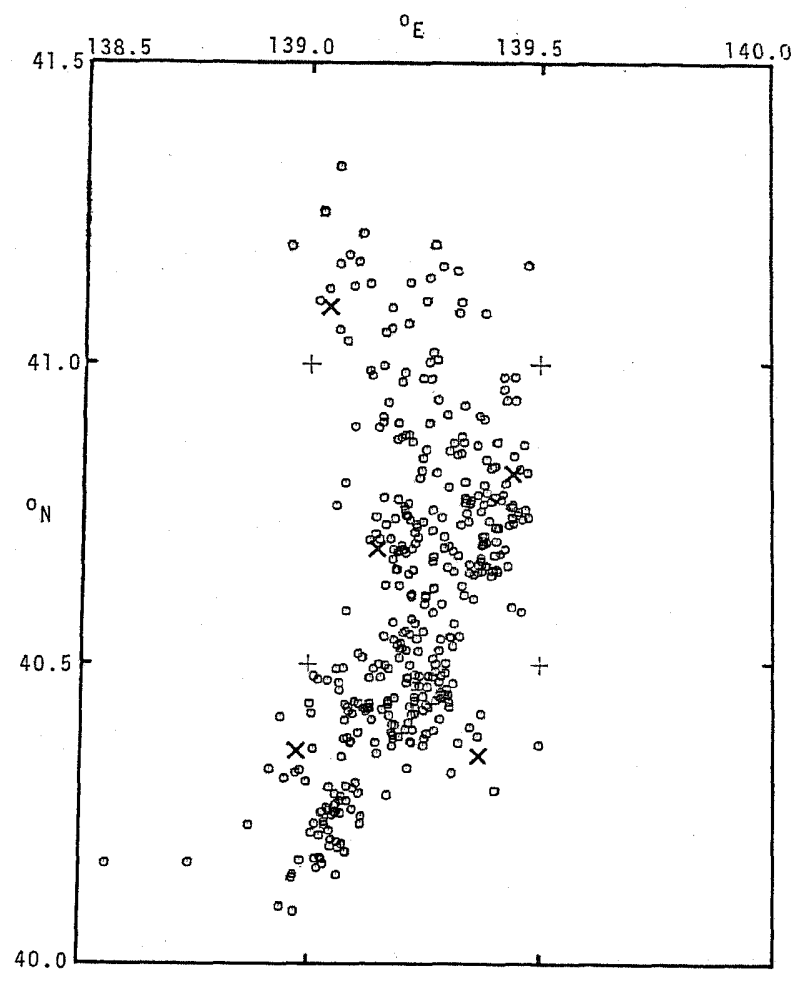

Fig. 5. Aftershock distribution determined from OBS data. All the hypocenters that properly converged are plotted. The number of the hypocenters is 405 . The crosses designate the OBS stations.

probable error in the initial guess was assumed to be large $(20 \mathrm{~km}$ for location and $5 \mathrm{~s}$ for origin time) in order that the given initial guess might have little effect on the resultant hypocenter location. The error of the obtained hypocenter was estimated by assuming the error of arrival time data to be one percent of its travel time.

\section{Results and Discussion}

Figure 5 shows the horizontal distribution of the hypocenters converged properly in the calculation. The number of the hypocenters is 405 . The general pattern of the aftershock distribution during the observation period is represented by Fig. 5 . The aftershock area is about $140 \mathrm{~km}$ long in the north-south direction with a width of $40 \mathrm{~km}$. The epicenter of the mainshock determined by the OCEP of Tohoku University (Fig. 1) is located at the southern part of the aftershock area. The distribution of the aftershocks narrows at around $40.6^{\circ} \mathrm{N}$, and the northern part trends toward the north and the southern part toward the 


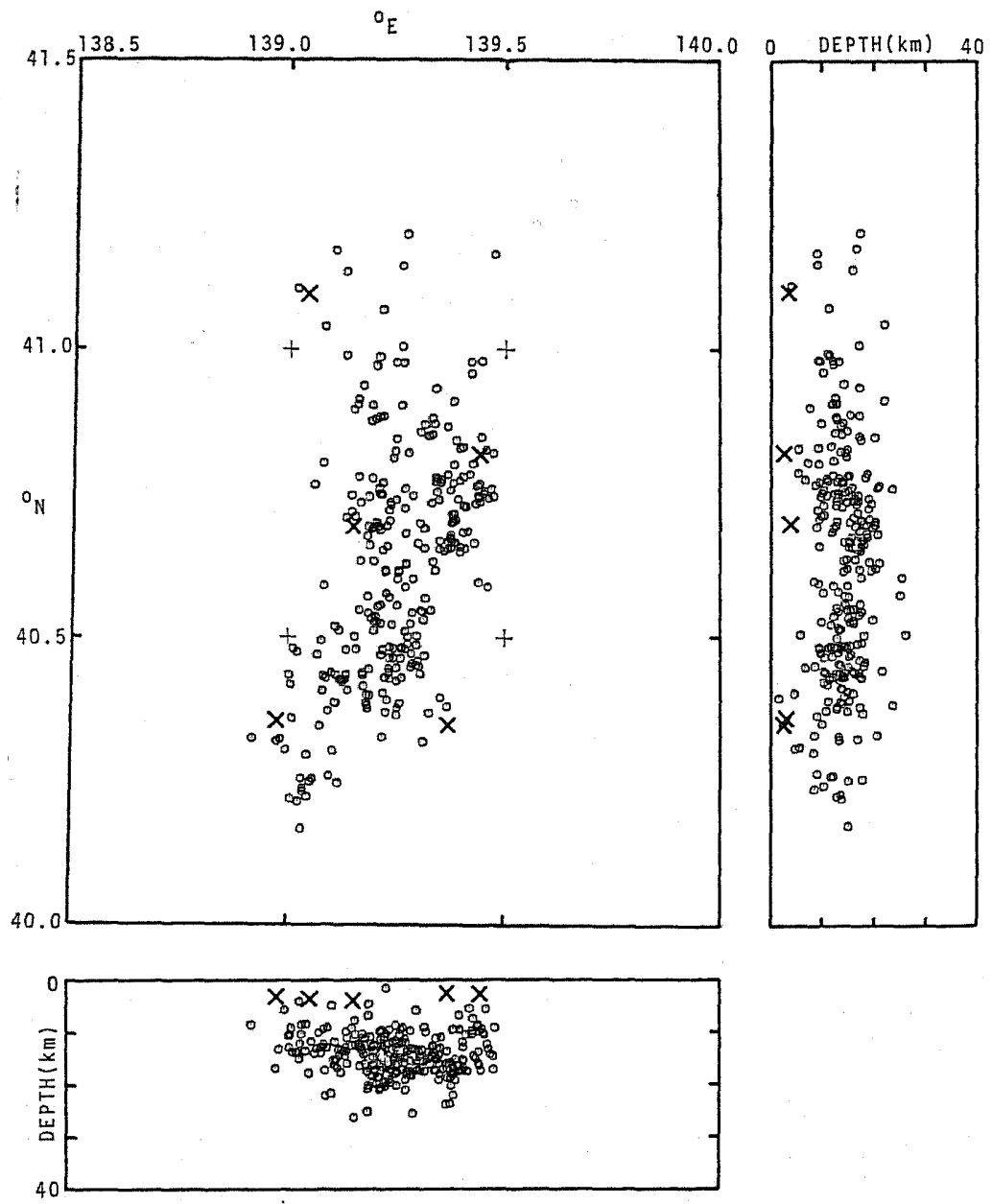

Fig. 6. Hypocenters with better accuracies. The estimated errors of the location are less than $3 \mathrm{~km}$ and the differences between the observed and calculated arrival times are less than $0.3 \mathrm{~s}$ for all the stations. Horizontal distribution, N-S (right), and E-W (bottom) cross sections are shown. The depth is referred to the sea level. The crosses designate the OBS stations.

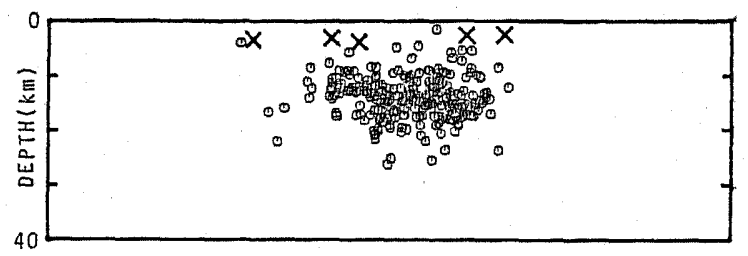

Fig. 7. A vertical cross section of the hypocenters presented in Fig. 6 as viewed from a direction of $\mathrm{S} 15^{\circ} \mathrm{W}$. The crosses designate the OBS stations. 

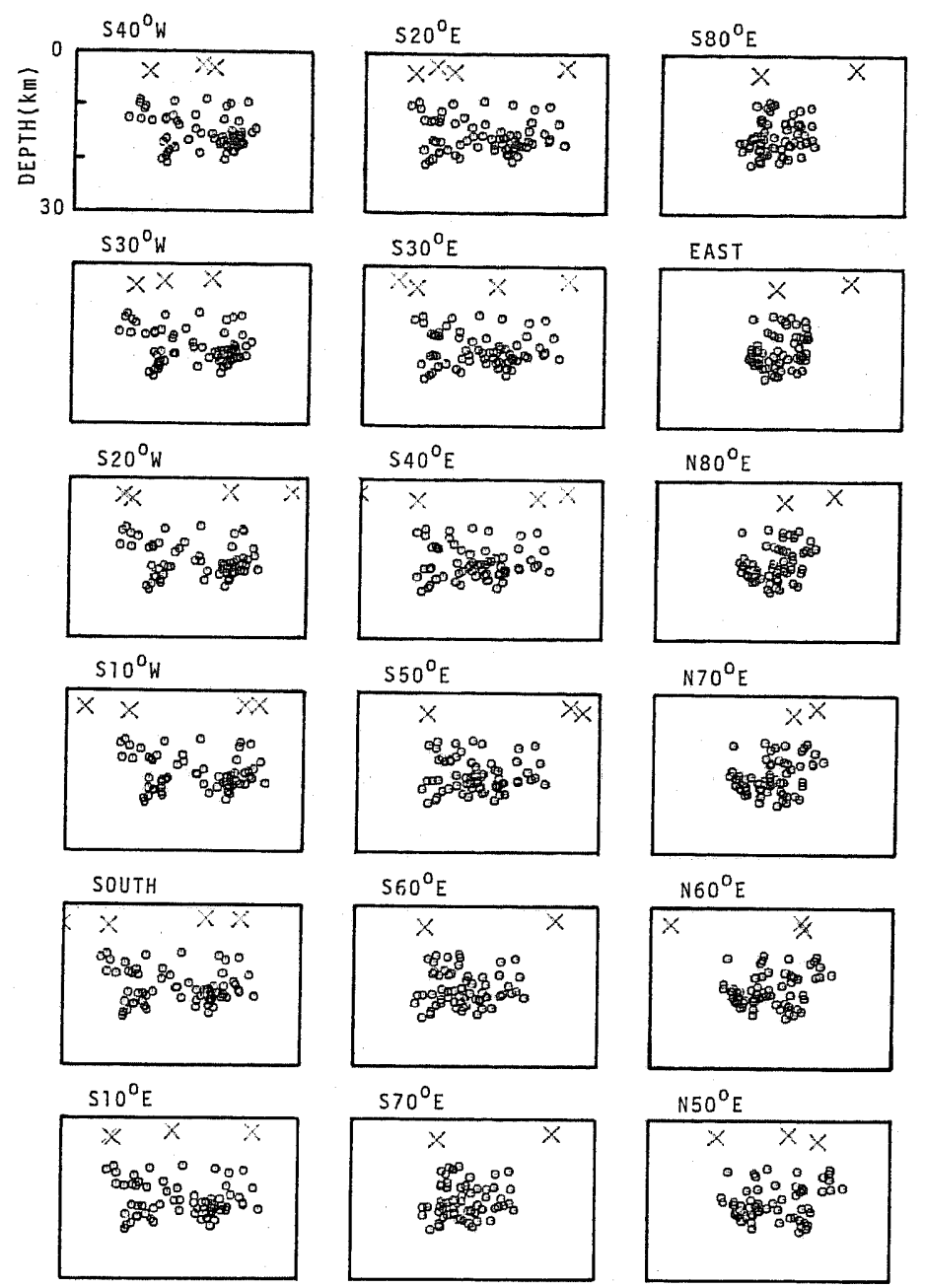

Fig. 8. Vertical distributions of the aftershocks located at the north of $40.6^{\circ} \mathrm{N}$ viewed from 18 directions by a $10^{\circ}$ increment. The crosses designate the OBS stations. The set of hypocenters is the same as that in Fig. 6.

southwest. Since the hypocenters in Fig. 5 have not been selected on the basis of their estimation errors, it is not appropriate to observe detailed structure of the aftershock distribution in Fig. 5.

In Fig. 6, the hypocenters selected according to the following criterion of the estimation error are plotted; the error of location is less than $3 \mathrm{~km}$ and the difference between the arrival time of the observation and that of the calculation (O-C time) is less than $0.3 \mathrm{~s}$ for all the stations. The number of hypocenters plotted here is 276. Although some of the hypocenters located outside the OBS network are not plotted in Fig. 6 because of their poor estimated accuracies, Fig. 6 gives spatially uniform data inside the OBS network. 

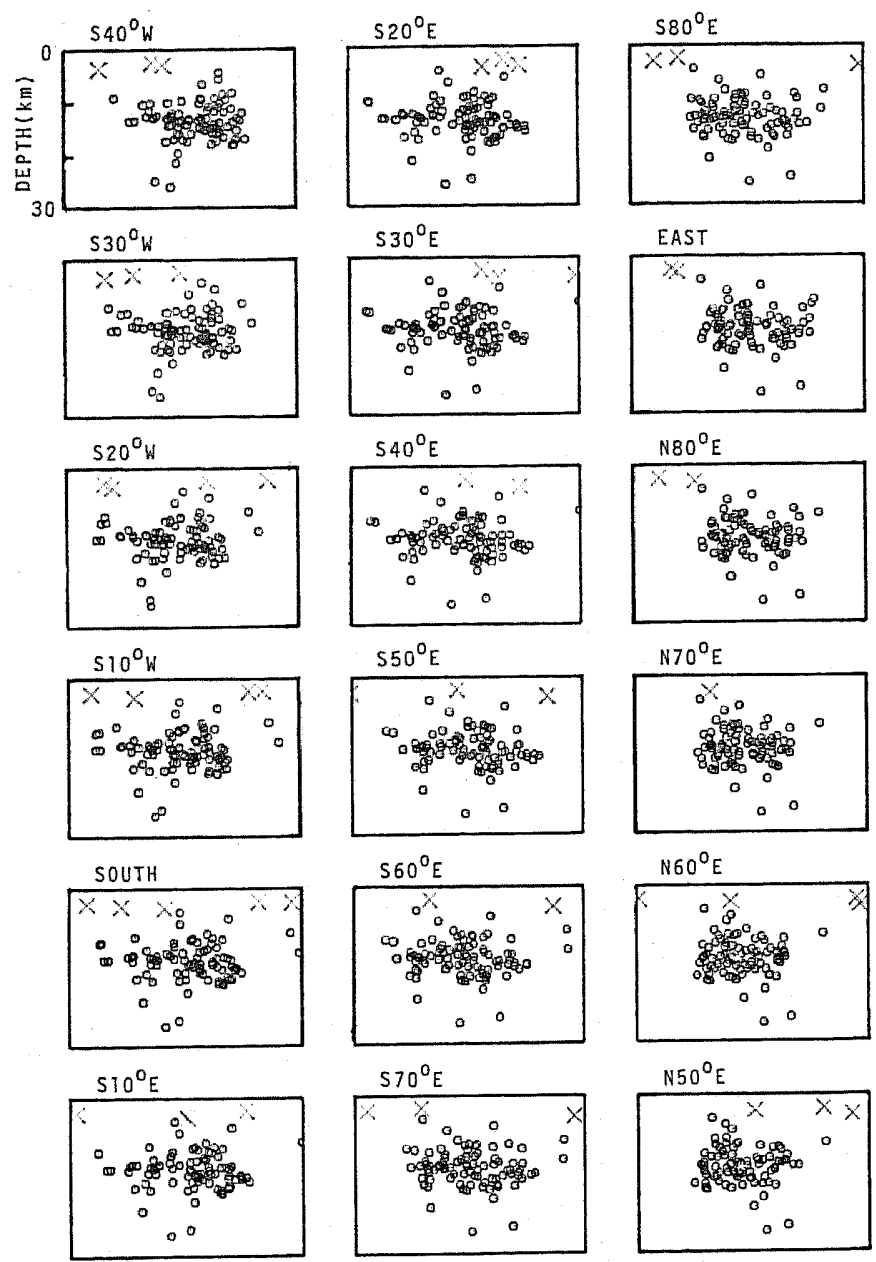

Fig. 9. Vertical distributions of the aftershocks located at the south of $40.6^{\circ} \mathrm{N}$ viewed from 18 directions by a $10^{\circ}$ increment. The crosses designate the OBS stations. The set of hypocenters is the same as that in Fig. 6.

In comparison with the epicenters obtained from the OBSs, those obtained from the land network of the OCEP of Tohoku University are shifted systematically westward by about $5 \mathrm{~km}$ on the average.

The vertical cross sections in Fig. 6 show that the focal depths of most of the aftershocks ranged from 8 to $21 \mathrm{~km}$ below sea level. They can not exceed $30 \mathrm{~km}$ even if the possible errors in the velocity structure model are considered. Since the lithosphere of the source region is more than $30 \mathrm{~km}$ thick as stated above, we can safely say that the hypocenters of the aftershocks were distributed in the middle and upper part of the lithosphere. In other words, the fracture did not span the entire lithosphere, and it was mainly in the crust. 
In the N-S cross section in Fig. 6, no general trend of the hypocenters which indicates a geometry of the fault plane seems to exist. On the other hand, in the E-W cross section, a dense part of the hypocenter distribution dips slightly eastward. This dip becomes most obvious when it is viewed from a direction of $\mathrm{S}$ $15^{\circ} \mathrm{W}$ (Fig. 7). The concentration of the hypocenters forms a plane arrangement. A dense distribution, which is about $5 \mathrm{~km}$ thick and $30 \mathrm{~km}$ long, dips eastward by about $15^{\circ}$.

This observation is consistent with the mechanism solution deduced from land station data. The mainshock has been considered a multiple shock because the forms of its body waves observed at the land stations are complex (IsHIKAWA et al., 1983). Several mechanism solutions have been obtained for the events which made up the mainshock: TAKAHASHI et al. (1983), IsHIKAWA et al. (1983), and SHIMAZAKI and MORI (1983). These mechanism solutions agree well with each other; they have an almost horizontal null vector directing to $\mathrm{N} 15$ to $20^{\circ} \mathrm{E}$, and an eastward dipping nodal plane with a dip $=25$ to $35^{\circ}$ and a westward dipping one with a dip $=55$ to $65^{\circ}$. From this mechanism solution and the aftershock distribution in Fig. 7, it is concluded that the main fault is the eastward-dipping low-angle one, although the dip angles are somewhat different.

Figures 8 and 9 show the vertical distributions of the hypocenters located at the north and the south of $40.6^{\circ} \mathrm{N}$, respectively, viewed from 18 directions by a $10^{\circ}$ increment. The eastward-dipping configurations of the hypocenter distributions are recognized in the views from certain ranges of directions; from S 0 to $20^{\circ} \mathrm{W}$ in the northern part (Fig. 8), and from $\mathrm{S} 20$ to $40^{\circ} \mathrm{W}$ in the southern part (Fig. 9). In these views, however, there are some hypocenters which do not belong to the eastward-dipping group. These hypocenters may suggest the existence of another major fault, therefore the complexity of the faulting process.

\section{Conclusions}

Five OBSs were deployed in the source region of the 1983 Japan Sea earthquake only three days after the occurrence of the mainshock using a helicopter. The observation was successful. The major part of the aftershock area was covered by the OBS network, and a 12 day continuous record was obtained.

Hypocenter determination was tried for 442 aftershocks whose $\mathrm{P}$ arrival times were picked with an accuracy of $0.1 \mathrm{~s}$ at four or five OBS stations. A precise aftershock distribution was obtained and it revealed important features of the 1983 Japan Sea earthquake which are difficult to resolve from land observations.

The aftershock area, which ran along the eastern margin of the Japan Basin, was $140 \mathrm{~km}$ long in north-south and $40 \mathrm{~km}$ wide. It narrowed at the middle of its length. Their focal depths concentrated in the range of 8 to $21 \mathrm{~km}$. Since the lithosphere of this region is estimated to be thicker than $30 \mathrm{~km}$, the fracture did not span the entire lithosphere but probably occurred mainly in the crust. 
The geometry of the main fault was suggested by a plane arrangement of the aftershock distribution, which is $30 \mathrm{~km}$ long in north-south and dips eastward by 15 to $25^{\circ}$. This observation is consistent with the mechanism solution of the mainshock obtained from land data. Not a few hypocenters which do not belong to the eastward-dipping plane may suggest the existence of another major fault plane.

We express our thanks to the Hydrographic Department of the Japan Maritime Safety Agency for providing the acoustic survey data, and to the Observation Center for Earthquake Prediction of Tohoku University for providing the hypocenter data which we used as the initial value. We are also grateful to R/V Shoyo of the Hydrographic Department and Mr. Y. Kuwahara for their help at the OBS recovery operation.

The hypocenter determination calculation was done at the Computer Center of Kyushu University.

\section{REFERENCES}

ABE, K., Re-examination of the fault model for the Niigata earthquake of 1964, J. Phys. Earth, 23, 349-366, 1975.

ABE, K. and H. KANAMORI, Mantle structure beneath the Japan Sea as revealed by surface waves, Bull. Earthq. Res. Inst., 48, 1011-1021, 1970.

Evans, J. R., K. SUYEHIRo, and I. S. SACKs, Mantle structure beneath the Japan Sea-a re-examination, Geophys. Res. Lett., 5, 487-490, 1978.

Faculty of SCIEnCE, Tohoku University and Faculty of SCIENCE, Hirosaki University, Foreshock and aftershock activities of the 1983 Central Japan Sea Earthquake, Rep. Coord. Comm. Earthq. Predict., 31, 22-33, 1984.

FuKAO, Y. and M. FuRUMOTO, Mechanism of large earthquakes along the eastern margin of the Japan Sea, Tectonophysics, 25, 247-266, 1975.

Hatori, T. and M. KaTAYAMA, Tsunami behavior and source areas of historical tsunamis in the Japan Sea, Bull. Earthq. Res. Inst., 52, 49-70, 1977 (in Japanese with English abstract).

ICHIKAWA, M., Reanalyses of mechanism of earthquakes which occurred in and near Japan, and statistical studies on the nodal plane solutions obtained, 1926-1968, Geophys. Mag., 35, 207274, 1971.

Ishikawa, Y., M. Takeo, M. Katsumata, M. Takahashi, S. Kashiwabara, and N. Mikami, Source process of the 1983 Japan Sea earthquake-(1) multiple shock and source mechanism, Programme Abstr. Seismol. Soc. Jpn., 1983(2), 19 (in Japanese).

Iwasaki, T., N. Hirata, K. Suyehiro, T. Kanazawa, T. Urabe, T. Moriya, and H. Shimamura, Aftershock distribution of the 1982 Urakawa-Oki earthquake determined by ocean bottom seismographic and land observations, J. Phys. Earth, 31, 299-328, 1983.

LudwiG, W., S. MurauchI, and R. Houtz, Sediments and structure of the Japan Sea, Geol. Soc. Am. Bull., 86, 651-664, 1975.

MATSU'URA, M. and N. HIRATA, Generalized least-squares solutions to quasi-linear inverse problems with a priori information, J. Phys. Earth, 30, 451-468, 1982.

Matsu'Ura, M., T. Yamada, K. Shibuya, H. Inatant, T. Tanimoto, N. Hirata, and J. Ito, Aftershock observation of the Miyagi-Oki earthquake by ocean bottom seismographs 2, Programme Abstr. Seismol. Soc. Jpn., 1978(2), 4 (in Japanese).

Okada, H., T. Moriya, T. Masuda, T. Hasegawa, S. Asano, K. Kasahara, A. IKami, H. Aoki, Y. SASAKI, N. HarukaWA, and K. Matsumura, Velocity anisotropy in the Sea of Japan as revealed by big explosions, J. Phys. Earth, 26 Suppl., 491-502, 1978. 
ShimaZAKI, K. and J. Mori, Focal mechanism of the May 26, 1983 Japan Sea earthquake, Programme Abstr. Seismol. Soc. Jpn., 1983(2), 15.

Takahashi, M., N. Nishide, A. Fukutome, M. Komiya, K. Sato, Y. Kambayashi, K. Sakuma, H. Yokoyama, and K. YoshikaWA, An outline of the mainshock of the 1983 Japan Sea earthquake, Programme Abstr. Seismol. Soc. Jpn., 1983(2), 1 (in Japanese).

URABE, T. and N. HrRatA, A playback system for long-term analog tape recordings of ocean bottom seismographs, Zisin, 37, 633-645, 1984 (in Japanese with English abstract).

URABE, T. and T. KANAZAWA, A high reliable timer for a pop-up OBS system, Zisin, 37, 511513, 1984 (in Japanese).

YAMADA, T., Spatial distribution of microearthquakes and crustal structure revealed by ocean bottom seismographic observation, $\mathrm{Ph}$. D. thesis, the University of Tokyo, 1980.

YAmada, T., T. AsadA, and H. Shimamura, A pop-up ocean bottom seismograph system, Programme Abstr. Seismol. Soc. Jpn., 1981(2), 126 (in Japanese).

Yamada, T., H. Inatani, M. Matsu'Ura, K. ShibuXa, T. Tanimoto, H. Hirata, T. Asada, E. MURAKAMI, and A. TAKAGI, Aftershock observation of the Miyagi-Oki earthquake by ocean bottom seismographs 1, Programme Abstr. Seismol. Soc. Jpn., 1978(2), 31 (in Japanese).

Yoshi, T. and S. Asano, Time-term analyses of explosion seismic data, J. Phys. Earth, 20, 47-57, 1972. 